\title{
Daylight availability in courtyards of urban dwellings in Athens
}

\author{
E. Tsianaka \\ RMJM London Ltd., Cambridge, UK
}

\begin{abstract}
The aim of this paper is to explore the role of courtyards in relation to daylight availability in urban dwellings in Athens. A previous study, which investigated the relation between the geometry of courtyards and air temperature, indicated that the lower floors of the dwellings, facing courtyards, were considerably cooler than those facing streets. Hence, courtyards tend to be valuable spaces for the city of Athens, contrary to streets, which are warmer, noisier and more polluted. The same study also showed that in high density areas, narrow courtyards are more beneficial than wider courtyards. However, this raises new questions: Do the narrow courtyards satisfy the recommended daylight levels? What is the opinion of occupants? Do the residents consider their apartments well day-lit? Are they happy staying in lower floor facing courtyards? This study examines the advantages and disadvantages of open spaces in Athens in the form of streets and courtyards addressing luminous conditions.
\end{abstract}

Keywords: courtyard, street, day-lit space, daylight factor, occupant views.

\section{Introduction}

The geometry of an urban area, the choice of the building materials and the surface properties of the dwellings, significantly affect its micro-climate $[1,2]$. The city of Athens is mainly composed of small blocks and a large number of apartment blocks that cover most of the ground, except the courtyard area. The comparison between the Amerikis and Omonias sites, two different case study sites in the centre of Athens, revealed that in high density areas, narrow courtyards are more beneficial than wider courtyards [3].

The examination of daylight availability inside the flats is considered essential for the comparison of visual comfort of the street and courtyard sides. The narrow courtyards seem to be cooler and reduce glare; however, do they satisfy the recommended daylight levels? Spot monitoring of light levels and 
occupant views, based on questionnaires, are used to evaluate the daylight levels in two typical buildings of the Amerikis and Omonias areas.

This paper consists of three sections. The first aims to familiarise the reader with the urban form of Athens and the particular characteristics of the two selected sites. The second includes the daylighting analysis, where spot monitoring of light levels, computer modelling using environmental prediction software Ecotect and occupants views based on questionnaires are used to appraise the daylight levels. The last evaluates the results and concludes the investigation.

\section{Case study}

\subsection{Climate and urban form of Athens}

Athens is a city of approximately four and a half million people and is located in the centre of Greece with latitude and longitude $38.04^{\circ}$ and $-23.38^{\circ}$ respectively. The climate is typically Mediterranean, moderate with sunny, dry and hot summers, mild, and damp winters. The average outdoor temperature is $15.7^{\circ} \mathrm{C}$ in winter and $19.8^{\circ} \mathrm{C}$ in summer [4].

The urban form of Athens is the result of the uncontrolled activity of building construction in the 1960s and 1970s, which was carried out not by the state and by private developers [5]. The city layout is quite typical with small blocks and narrow streets. Eight-storey apartment blocks and two-storey neo-classical houses cover approximately $70 \%$ of the block with a back-yard at the core of each block, known as a courtyard, figs 1 and 2. The courtyard, a result of regulations due to the high building density, is an irregularly shaped space, usually without plants and trees, designed mainly with the purpose of providing daylight and ventilation to the back rooms. There are single aspect dwellings looking only on to the courtyard or street side, but the majority of dwellings are dual aspect flats facing both courtyard and street. A typical design characteristic of the residential buildings in the city centre is the penthouses, i.e., flats with a terrace on the roof of the buildings, fig. 3 .

The usual building structure consists of a concrete frame with solid brick partitions and light-coloured plaster covering most of the surfaces, which is a typical characteristic of Mediterranean architecture. The windows are usually single glazed within timber frames with shutters.

\subsection{The Amerikis and Omonias Sites}

Two case study sites were selected to determine the relationship between urban form and daylighting, and between the street side and courtyard side. The Amerikis site is located around Amerikis Square to the north-east side of the city centre, fig. 1. It is a middle-class residential area with six storey high buildings usually incorporating retail and offices on the ground floor. The Omonias site is situated closer to the city centre around Omonias Square, one of the reference points in Athens, fig. 2. The buildings are up to eleven storeys high but the average is eight storeys. The lower levels are occupied by shops and offices, 
while the upper levels house either offices or flats. Comparing the two sites, the Amerikis comprises of lower buildings with wider courtyards and narrower streets than those of Omonias, fig. 3.

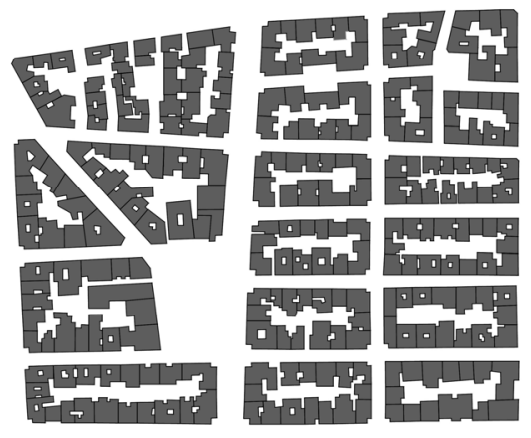

Figure 1: $\quad$ Black and white figure ground map of the Amerikis site, where black corresponds to built-up area and white to open space.

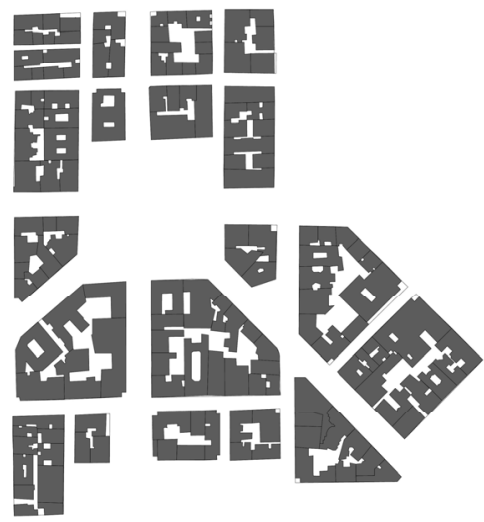

Figure 2: $\quad$ Black and white figure ground map of the Omonias site, where black corresponds to built-up area and white to open space.

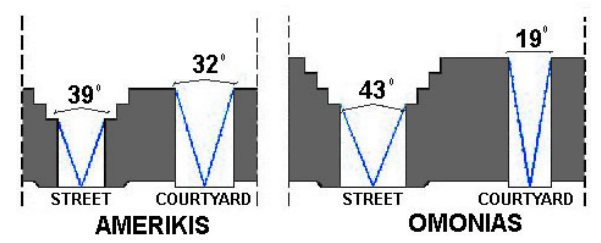

Figure 3: Typical sections of the Amerikis and Omonias sites.

The morphological and topological analysis of the two sites in [3] concluded that the courtyard widths are similar to those of the streets. The closer to the city centre an area is, the larger the street width and the smaller the courtyard width. In the Omonias area, the average courtyard width is $9.1 \mathrm{~m}$ and the street width $14.1 \mathrm{~m}$, whereas in the Amerikis, the average courtyard width is $12.5 \mathrm{~m}$ and the street width is $10.3 \mathrm{~m}$. However, the sky view angles of the two sides are different due to the penthouses formed only on the last floors of the street side as it is illustrated in fig. 3. Hence, the street side of the Athenian buildings receives more solar radiation compared with the courtyard side on account of the larger sky view angles of the streets.

Direct solar radiation does not reach into the ground level of the buildings in Athens before March, which is the end of the heating season in Greece. Depending on the direction of the streets, the width, or length of the courtyard, 
and the height of the surrounding buildings, no more than two or three floors are in sun view throughout the winter.

\section{Daylighting analysis}

\subsection{Spot monitoring}

Spot monitoring of light levels was carried out between 18 and 23 May 2004 in two urban areas of the Amerikis and Omonias. The first three days concentrated on the street side and the other three on the courtyard side.

The measurements were performed in one typical building of each selected site in rooms looking either to the street, or courtyard, in lower and upper levels from 07:00 to 19:00. Illuminance values in lux were sampled using a digital light meter and were then converted to daylight factors. The daylight factor, a percentage ratio of the instantaneous illumination level at a reference point inside a room to that occurring simultaneously outside in an unobstructed position [6], is a good indicator of interior brightness and daylight availability. As it is not practical to express daylighting conditions inside a building at any time, due to continuous corresponding changes of the sky luminance, the daylight factor was considered a good reference for judgment of visual comfort. The light meter was fully cosine corrected for angular incidence of light with ranging from 0 lux to 50,000 lux. The reflections, glare, shadows and the areas of bright contrast made the illuminance monitoring difficult. For this reason, the use of computer modelling to augment the data was felt to be necessary.

Table 1: Global radiation in $\mathrm{W} / \mathrm{m}^{2}$ [7].

\begin{tabular}{|c|c|c|c|c|c|c|}
\hline & 18 May & 19 May & 20 May & 21 May & 22 May & 23 May \\
\hline Global Radiation $\left(\mathrm{W} / \mathrm{m}^{2}\right)$ & 211 & 265 & 289 & 387 & 527 & 515 \\
\hline
\end{tabular}

May 2004 in Athens was a relatively dry month, being partly cloudy most of the days. For a better understanding of the intensity of solar radiation, table 1 presents global radiation data $\left(\mathrm{W} / \mathrm{m}^{2}\right)$ for the time period during which the experiment was performed. The latter days of May from $21^{\text {st }}$ to $23^{\text {rd }}$ had higher radiation levels compared with the earliest ones from $18^{\text {th }}$ to $20^{\text {th }}$ May.

Figures 4 and 5 illustrate the daylight factor obtained from indoor and outdoor measurements for the two selected sites comparing the street side with the courtyard side. On both case study areas, the street side has higher average daylight factor values (Amerikis 3.6\%, Omonia 6.1\%) than the courtyard ones (Amerikis 4.5\%, Omonias 3.6\%). This is due to the large width of the street and the greater sky view angles of the Omonias streets. On the courtyard side, the Amerikis rooms have the greater figures having the wider courtyard widths (6.9\% on upper levels and $2.0 \%$ on lower levels).

Table 2 displays the relation between daylighting and building level; lower floor-facing and upper floor-facing flats. The lower a dwelling is located, the lower the daylighting value it receives. In particular, in the Omonias case, on the courtyard side, the daylight factor rose from $1.5 \%$ on the ground to $5.7 \%$ on the top level. 


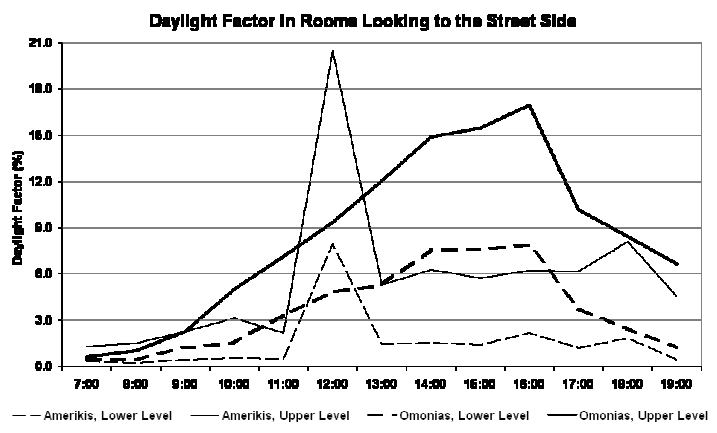

Figure 4: Daylight Factor $(\%)$ measured in rooms looking on to the street side.

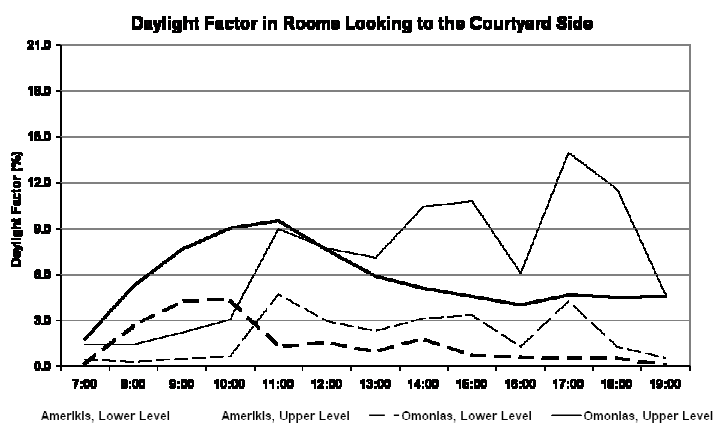

Figure 5: Daylight factor measured in rooms looking on to the courtyard side.

In general, the daylight factors appear to be satisfied for both sides compared to typical recommended minimum factors in rooms with side lighting only in domestic buildings of the British Standards on Lighting [8] as shown in table 3.

At this point it is worth mentioning that the Greek Building Regulations also include daylighting criteria for domestic buildings [9] with the recommendation that all the main usable spaces and sleeping rooms should provide adequate direct and reflected light for residents. However, the recommended daylight criteria is limited to the minimum glazing ratio of $10 \%$ in relation to the gross internal domestic space area without reference to daylight factor [9].

According to the British CIBSE Guide [10] and German DIN 5035 [11] a room with an average daylight factor of more than 5\% is regarded as well day-lit, that is electric lights would be used infrequently during daylight hours, but below $2 \%$ electric lights would be used frequently [10]. Hence, the upper-floor flats of both Amerikis and Omonias sites could be considered well day-lit spaces compared to lower ones. The daylight conditions of the lower floor-facing courtyard flat in the Omonias are fairly poor with an average of $1.5 \%$. As an 
Table 2: Average measured daylight factor in $\%$ of the Amerikis and Omonias sites in relation to building level.

\begin{tabular}{|l|c|c|}
\hline \multicolumn{2}{|c|}{ Average Measured Daylight Factor (\%) } \\
\hline & \multicolumn{2}{|c|}{ Street Side } \\
\hline & Lower Level & Upper Level \\
\hline Amerikis & 1.5 & 5.6 \\
\hline Omonias & 3.7 & 8.5 \\
\hline & \multicolumn{2}{|c|}{ Courtyard Side } \\
\hline & Lower Level & Upper Level \\
\hline Amerikis & 2.0 & 6.9 \\
\hline Omonias & 1.5 & 5.7 \\
\hline
\end{tabular}

Table 3: $\quad$ Recommended values of general or minimum daylight factor in buildings [8].

\begin{tabular}{|l|l|}
\hline Building Type & Recommended Daylight Factor (\%) \\
\hline Kitchen & 2.0 \\
\hline Living Room & 1.0 \\
\hline Bedroom & 0.5 \\
\hline
\end{tabular}

eastern oriented flat the highest daylight factor occurs at 10:00 local time $(4.41 \%)$ while the lowest at 19:00 (0.15\%).

According to British Standards recommendations, the average 1.5\% seems to be acceptable for sitting and sleeping spaces but not acceptable for working spaces such as kitchens. Note that the measured daylighting factor levels, especially of the critical lower floor-facing rooms of the Amerikis and Omonias sites, are marginal and the use of computer modelling to evaluate these daylighting data is considered essential.

\subsection{Computer modelling}

Two computer models of two typical buildings were created to explore the daylight factor of lower-floor facing courtyard flats of each case study site. Ecotect v5.2 [12] was employed to perform this analysis as an environmental prediction software, primarily designed to evaluate daylight penetration, that is simple to use, quick to learn and produces reasonably accurate results in daylighting analysis [13]. The models were constructed with sufficient detail except for the wall surfaces and windows, which were designed with greater detail in terms of materials and colours. On considering the effect of furniture, it was decided to be omitted from the model.

The results of the daylighting analysis of the lower-floor-facing courtyard rooms of Amerikis and Omonias are presented in table 4. The daylight factor of Amerikis courtyard room from $07: 00$ to $19: 00$ was calculated $2.9 \%$ slightly higher than the spotting monitoring results $(2.0 \%)$, while the daylight factor of Omonias courtyard room was $1.2 \%$; an even lower level to measured results (1.5\%). 
Table 3: Light levels and daylight factors of the lower floor-facing courtyard flats of the Amerikis and Omonias areas deriving from computer modelling.

\begin{tabular}{|l|l|l|}
\hline & Light Levels (Lux) & Average Daylight Factor (\%) \\
\hline Amerikis & 295 & 2.9 \\
\hline Omonias & 125 & 1.2 \\
\hline
\end{tabular}

\subsection{Questionnaires}

Residents from both sites were questioned about their opinion on the visual performance of their dwellings. A two part questionnaire was set up: the first being a demographic survey and the second containing key questions of visual and thermal comfort. This paper considers only the questions regarding daylighting availability. 80 letters were sent to the residents of the Amerikis and Omonias areas living on different levels of buildings. Finally, 46 inhabitants were willing to answer the questions and return the questionnaires. Due to the relatively small number of participants, the results are interpreted qualitatively.

$30 \%$ of the participants were men and $70 \%$ women. Most age groups took part in the survey but the majority were young people between 18 and 25 years old. Regarding the area of living, 35 of the people interviewed lived in Amerikis and only 11 in Omonias. This was expected due to the mixed use character of the Omonias site. Concerning the layout of the dwellings, at least half of the flats are dual aspect dwellings looking on both courtyard and street sides (52\%) and are fortunate to have cross ventilation, fig. 6 .

The second part of the survey consisted of the following questions and possible answers:

1. Do you consider your flat day-lit?

No, I would prefer more sun / No, but I am satisfied / Yes, but I would prefer more / Yes, ok / Yes, but too much sun

2. What do you consider more important when you choose accommodation:

A well day-lit space / A cool flat

3. If you consider your flat well day-lit, during the summer time, do you feel hot at your dwelling?

Yes, too hot / Yes / Comfortable / Cool

Most respondents expressed the view that they are satisfied with their dwellings with regard to daylight availability. $80 \%$ of the questioners replied positively that they consider their flats to be well day-lit, while $20 \%$ replied negatively, fig. 7 .

Regarding the positive answers, fig. 7 , it is interesting that $46 \%$ of the occupants responded that they consider their dwelling day-lit while $28 \%$ others, even if they consider that they live in a well day-lit space, they would be happier if their dwelling was even better day-lit. In addition to this, only $7 \%$ of the positive responses reflect the opinion that the flats receive too much sun.

Concerning the courtyard and street sides, although most of the interviewees answered positively, the majority of inhabitants of the single aspect courtyard flats replied negatively $(72 \%)$. However, two third of these people answered that even if their courtyard-facing flats are not sunny, they are satisfied. 


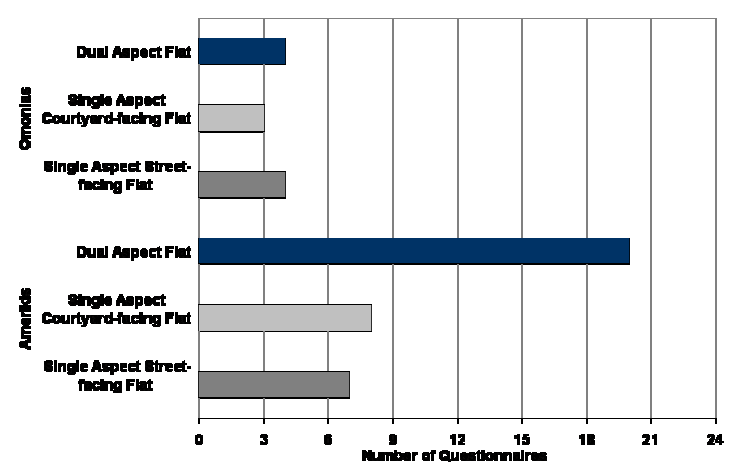

Figure 6: $\quad$ Single and dual aspect flats.

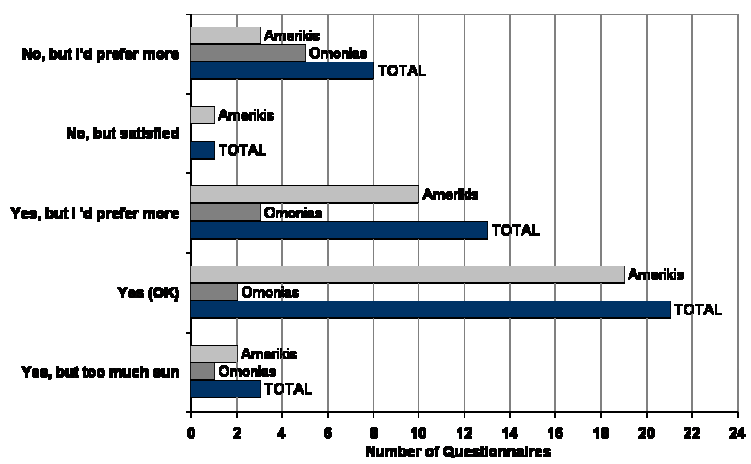

Figure 7: Distribution of the answers to the question 'Do you consider your flat day-lit?'.

In addition to this, the classification according to floor levels, fig. 8, shows that the residents who answered 'No, I would prefer more' or 'No, but I am satisfied' were those living on the lower levels. There seems to be a difference between inhabitants of the Amerikis and Omonias sites. In Omonias site, more people living in the bottom levels would prefer to live in sunnier flats rather than Amerikis ones.

28 out of 46 respondents, when asked to choose between a well day-lit flat and cool flat answered that they would prefer to live in a cool space $(61 \%)$. Due to the comparatively small difference of replies, the interpretation becomes complicated. We could only highlight the tendency of responses in preference of cool flats to well day-lit ones.

The third question tried to combine the visual with the thermal comfort and at the same time to explain the slightly higher tendency of residents for cooler flats. On the one hand, the majority of Amerikis respondents (70\%) expressed the opinion that their flats were either 'Yes, too hot' or 'Yes, hot', fig. 9. On the other hand, the occupants of the Omonias site responded equally to all four questions, fig. 9. It is worth mentioning that the majority of courtyard-facing flat 


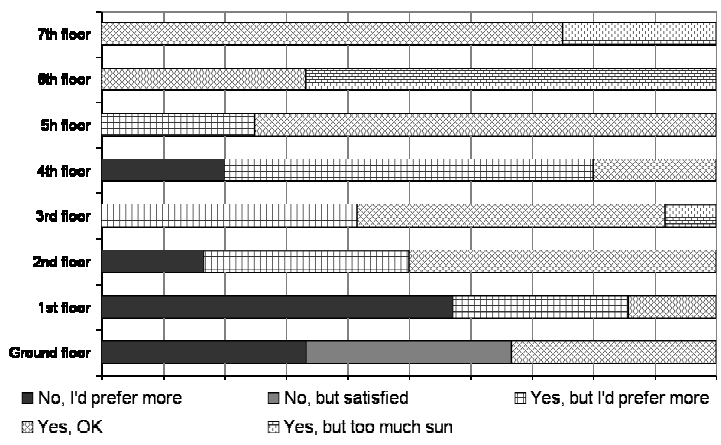

Figure 8: Distribution of the answers to the question 'Do you consider your flat day-lit?' classified by floor level.

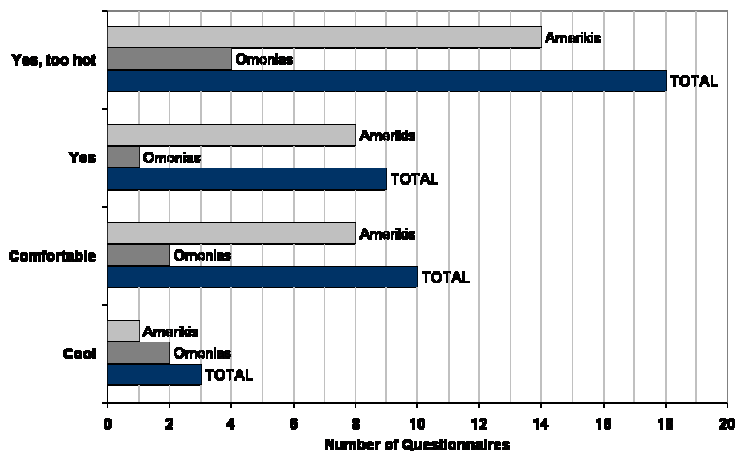

Figure 9: Distribution of the answers to the question 'If you consider your flat well day-lit, during the summer time, do you feel hot at your dwelling?'.

residents answered that they considered their dwellings either comfortable or cool for summer time.

\section{Conclusion}

The aim of the paper is to identify the benefits of courtyard facing flats in comparison to the street facing flats.

The thermal analysis of urban blocks in Athens in [3] revealed that courtyard facing rooms are cooler than street facing rooms. In addition, it has also been highlighted that the narrow courtyards and the lower floor-facing dwellings benefit more by having lower indoor temperatures [3]. However, the daylight availability of these dwellings was questionable.

The daylight analysis of this study demonstrated that the luminance conditions of the courtyard facing flats could be considered acceptable in accordance with recommended levels provided that the average daylight factor of $4.3 \%$. Regarding the upper and lower floor dwellings of the courtyard side, the upper flats are well day-lit with an average measured daylight factor of $6.3 \%$, 
while the lower flats are poorly day-lit with an average measured daylight factor of $1.8 \%$ and the computer modelled calculated to be $2.0 \%$. The minimum daylight factor was observed in the cooler lower floor-facing flats in the narrow courtyards of the Omonias site with a measurement of $1.5 \%$ and a computer calculated value of $1.2 \%$; a result of the different solar radiation received.

Inhabitants from both case study sites were questioned about their opinion on daylight availability of their homes. Most of them expressed the view that their dwellings are well day-lit. The majority of interviewees living on lower floorfacing courtyards of both the wider courtyards of the Amerikis and narrower courtyards of the Omonias replied that they were satisfied with the daylight conditions in their homes. It is worth highlighting the tendency of people living in warm climates to have a preference for cool spaces rather than well day-lit ones, mainly due to the fact that a well day-lit space is a warmer space.

Both thermal and daylight evaluation showed that courtyards tend to be valuable spaces for the city of Athens, contrary to streets, which are warmer, noisier and more polluted. The street facing flats could also benefit from courtyard lower temperatures by making use of the cool courtyard air by bringing it into the building via the courtyard facing flats.

\section{References}

[1] Givoni B., Climate Considerations in Building and Urban Design, Van Nostrand Reinhold, New York, 1998.

[2] Oke T.R., Boundary Layer Climates, Routledge, New York, 1987.

[3] Tsianaka E., The Role of Courtyards in Relation to Air Temperature of Urban Dwellings in Athens, Plea 2006, Geneva- Switzerland 2006, pp. 833-838, 2006.

[4] Remundet J.al., Meteonorm Software v4.0, Bern-Switzerland, 1999.

[5] Bastea E., The creation of modern Athens: Planning the myth, Cambridge University Press, Cambridge, 2000.

[6] Low Energy Architecture Research Unit of the London Metropolitan University available at http://www.learn.londonmet.ac.uk/packages

[7] National Technical University of Athens, available http://www.users.ntua.gr/jorgalan/kifissia

[8] BS 8206 Part 2, Code of Practice for Daylighting, London: British Standards Institution, 1992.

[9] Greek Building Regulations for Daylighting and Natural Ventilation, Article 11 of FEK-59/D/3-2-89 and Decision APOF-3046/304/89.

[10] CIBSE, Daylighting and Window Design, Lighting Guide LG10, 1999.

[11] Lohmeyer G., Praktische Bauphysik, B.G Teubner, Stuttgart - Germany, pp. 489-490, 1995.

[12] Marsh A., Ecotect Tool Software v5.2, Square One Research PTY Ltd., http://www.squ1.com

[13] Roberts A. and Marsh A., Ecotect: Environmental Prediction in Architectural Education, ECAADE, Helsinki - Finland (2001) available at http://www.tkk.fi/events/ecaade/E2001presentations/13_03_roberts.pdf 